\section{Public Health} Genomics
Public Health Genomics 2015;18:318-320

DOI: 10.1159/000435852
Received: June 10, 2015

Accepted: June 10, 2015

Published online: July 23, 2015

\title{
European Reference Networks and Guideline Development and Use: Challenges and Opportunities
}

\author{
Cristina Morciano $^{a}$ Paola Laricchiuta ${ }^{a}$ Domenica Taruscio $^{a}$ \\ Holger Schünemann ${ }^{b}$

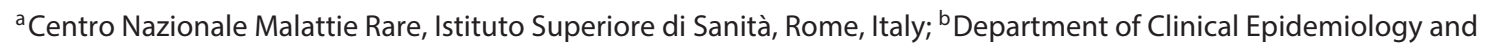 \\ Biostatistics, McMaster University, Hamilton, Ont., Canada
}

\section{Key Words}

European Reference Networks · Practice guidelines .

Rare diseases

\begin{abstract}
Background: The Directive 2011/24/EU [OJEU 2011, L88/45] on the application of patient rights in cross-border health care requires the European Commission to support Member States in the development of European reference networks (ERNs). These ERNs are meant to ease the access of patients to highly specialized health care and to facilitate the cooperation at the European Union level in particular medical domains where expertise is scarce, especially in the rare disease area. Methods: The Directive 2011/24/EU [OJEU 2011, L88/45] and the recent Commission Delegated Decision [OJEU 2014, L147/71] as well as the Implementing Decision [OJEU 2014, L147/79] require ERNs and health care providers wishing to join ERNs to have the capacity of developing good practices guidelines. Results: This provision results in a number of challenges but also opportunities for Member States with respect to guideline production. Member States could consider the importance of devoting resources to build efficient systems and capacities for the development and implementation of trustworthy guidelines. Furthermore, they could adopt a cooperative approach to optimize
\end{abstract}

guideline production across countries. Finally, they could promote the establishment of new research governance based on systematically identified research gaps and prioritized as well as communicated research recommendations. Conclusion: Member States are at a decisive point in establishing the details to ensure the transparent and effective functioning of ERNs. Producing explicit plans for the development and use of trustworthy guidelines should be an essential part of this effort.

(c) 2015 S. Karger AG, Basel

\section{Introduction}

The Directive 2011/24/EU is intended to provide a legal framework within the European Union (EU) to facilitate cross-border care [1]. Article 12 requires the European Commission to support the Member States in the establishment of the European reference networks (ERNs). ERNs should facilitate the cooperation at the EU level in particular medical domains with a focus on areas where expertise is scarce, facilitating the access to diagnosis and to high-quality health care, especially in the rare disease area. As such, the establishment of ERNs appears to have been the most important European cooperative initiative for decades.

\section{KARGER 125}

(c) 2015 S. Karger AG, Base

$1662-4246 / 15 / 0185-0318 \$ 39.50 / 0$

E-Mail karger@karger.com

www.karger.com/phg
Cristina Morciano

Centro Nazionale Malattie Rare, Istituto Superiore di Sanità

Viale Regina Elena, 299

IT-00161 Rome (Italy)

E-Mail cristina.morciano@iss.it 
However, the Directive 2011/24/EU [point (iii) of Art. 12(4)(a)] and the more recent Commission Delegated Decision 2014/286/EU [2] and Commission Implementing Decision 2014/287/EU [3] require that ERNs and health care providers wishing to join ERNs should have the capacity to develop good practice guidelines. This will pose challenges but also offer many opportunities to the Member States, which are discussed below.

\section{Discussion}

First, guideline production and implementation in the EU is far from satisfactory. Few countries have well-established systems in place sustained by national or local regulations that provide mechanisms for quality assurance, implementation and use of clinical guidelines. Many countries still rely on sporadic initiatives based on unclear processes, others lack the capacity for evidencebased guideline development or, even if they have the capacity, they lack a coordination of a central agency [4].

For these countries, the implementation of the Directive and the constitution of ERNs would be an excellent opportunity for (i) considering the importance of devoting resources to build an efficient system for developing and implementing guidelines, and (ii) ascertaining the actual capacity of health care providers for producing trustworthy guidelines according to international standards, especially of those wishing to join ERNs.

Second, it is unclear who and what structure will support ERNs in the production of guidelines. For instance, will ERNs pursue a cooperative approach aimed at sharing expertise, infrastructures and personnel, and at harmonizing their methodologies towards a 'cross-border guideline production'?

Although the cooperation across countries could optimize guideline production work and ameliorate quality assurance practices [5], as of yet and except for professional societies, there are no examples of sustained structures at the European level.

ERNs can be an opportunity for changing this and for initiating processes to establish European structures of cooperation in producing guidelines. Shifting away from a national or regional isolationism, this could lead to more equitable care across countries and a wider access for patients to care. This cooperation could be also initially triggered by the need of developing cross-border care pathways (as requested by the Directive) to assure a safe and well-functioning cross-border patient mobility.

European Reference Networks and Good Practice Guidelines
Third, it is unclear what procedures ERNs will establish to identify and fill research gaps as requested by the Directive. The lack of explicit mechanisms for biomedical and research prioritization is an issue that has been considered many times, heightening the need for a new research governance strategy that increases the transparency of the process, meets the need of research users and starts from the awareness of the ongoing research and all published evidence $[6,7]$.

Given the substantial momentum behind the constitution of ERNs, there is the opportunity to devise such new research governance. This could be facilitated if ERNs would consider guideline development processes to systematically identify research gaps and formulate, prioritize as well as properly communicate research recommendations to researchers and research funders. Advantages of this would arise not only from a greater transparency of the guideline process but also from a greater efficiency of the research machinery.

Interesting insights and useful tools to tackle the challenges outlined here and to take advantage of the opportunities behind them could come from the work of European-funded projects such as (i) the GRADE working group's EU-funded DECIDE project, aimed at developing strategies to improve the communication of evidencebased recommendations [8], (ii) the RARE-Bestpractices project [9], which is focused on facilitating the knowledge exchange on guidelines on rare diseases and (iii) the COMET initiative, set up to try to improve the usefulness of outcomes in research [10].

\section{Conclusions}

Member States are at a decisive point in establishing the details of the organizational structure of ERNs to support a range of activities where cooperation could yield significant benefit to European citizens. Producing explicit plans for the development and use of trustworthy guidelines should be an essential part of this effort, taking into account the existing work done within the framework of European initiatives.

\section{Disclosure Statement}

All authors are involved in the RARE-Bestpractices project and the project dissemination. Prof. Holger Schünemann is involved in the GRADE's DECIDE project and the project dissemination. 


\section{References}

1 European Parliament and Council of the European Union: Directive 2011/24/EU of the European Parliament and of the Council of 9 March 2011 on the application of patients' rights in cross-border health care. OJEU 2011, L88/45.

2 European Commission: Commission Delegated Decision 2014/286/EU of 10 March 2014 setting out criteria and conditions that European Reference Networks and healthcare providers wishing to join a European Reference Network must fulfill. OJEU 2014, L147/71.
3 European Commission: Commission Implementing Decision 2014/287/EU of 10 March 2014 setting out criteria for establishing and evaluating European Reference Networks and their members and for facilitating the exchange of information and expertise on establishing and evaluating such Networks. OJEU 2014, L147/79.

4 Legido-Quigley H, Panteli D, Brusamento S, et al: Clinical guidelines in the European Union: mapping the regulatory basis, development, quality control, implementation and evaluation across member states. Health Policy $2012 ; 107: 146-156$.

5 Schünemann HJ, Woodhead M, Anzueto A, et al: A vision statement on guideline development for respiratory disease: the example of COPD. Lancet 2009;373:774-779.
6 Liberati A: Need to realign patient-oriented and commercial and academic research. Lancet 2011;378:1777-1778.

7 Chalmers I, Bracken MB, Djulbegovic B, et al: How to increase value and reduce waste when research priorities are set. Lancet 2014;383: 156-165.

8 GRADE's DECIDE project. http://www.decide-collaboration.eu.

9 Rare-Bestpractices project. http://www.rarebestpractices.eu.

10 COMET Initiative. http://www.comet-initiative.org. 